\title{
MaxEnt Modeling for Predicting Impacts of Environmental Factors on the Potential Distribution of Artemisia aucheri and Bromus tomentellus-Festuca ovina in Iran
}

\author{
Javad Esfanjani ${ }^{1}$, Ardavan Ghorbani ${ }^{1 *}$, Mohammad Ali Zare Chahouki ${ }^{2}$ \\ ${ }^{1}$ Department of Range and Watershed Management, University of Mohaghegh Ardabili, Ardabil, Iran \\ ${ }^{2}$ Department of Rehabilitation of Arid and Mountainous Regions, University of Tehran, Iran
}

Received: 23 July 2017

Accepted: 19 August 2017

\begin{abstract}
The main goal of this study was to estimate the geographic distribution of Artemisia aucheri and Bromus tomentellus-Festuca ovina habitat using the maximum entropy modeling technique (MaxEnt) in the Chaharbagh rangeland of Golestan Province in Iran. Vegetation sampling was done using the random- systematic method. A total of 120 plots were placed in the study area. Soil samples were taken $0-30 \mathrm{~cm}$ (sampling of the soil due to the mountainous terrain and deep rooted plants, depths were determined at the $0-30 \mathrm{~cm}$ layer). Measured soil properties included texture, organic carbon, lime, $\mathrm{pH}, \mathrm{EC}$, and $\mathrm{N}$. Topographical data (obtained from a DEM map) was elevation, slope, and aspect. To prepare the data for being enterer into MaxEnt software, first the map of soil factors was obtained through the kriging method in GIS software. Then, for analysis, the elevation, and slope, geographic directions, and soil factors maps and the presence points of plant species were entered. Using the jackknife method and response curve we found the most important environmental predictor variables. Results showed that N, sand, and clay had the greatest impacts on the distribution of $A$. aucheri and $\mathrm{N}$, sand, silt, clay, and lime in soil had the greatest impacts on the distribution of B. tomentellus-F. ovina in the study area. Correspondence of actual map with the predictive one was assessed at a satisfactory level (Kappa coefficient $=0.05$ for $A$. aucheri but Kappa coefficient $=0.51$ for B. tomentellus-F. ovina). So MaxEnt method is the more successful in predicting $B$. tomentellus- $F$. ovina habitat than A. aucheri habitat, because the distribution of $A$. aucheri habitat was vast and outspread in the study area.
\end{abstract}

Keywords: MaxEnt, jackknife method, AUC, Chaharbagh rangeland

*e-mail: a_ghorbani@uma.ac.ir 


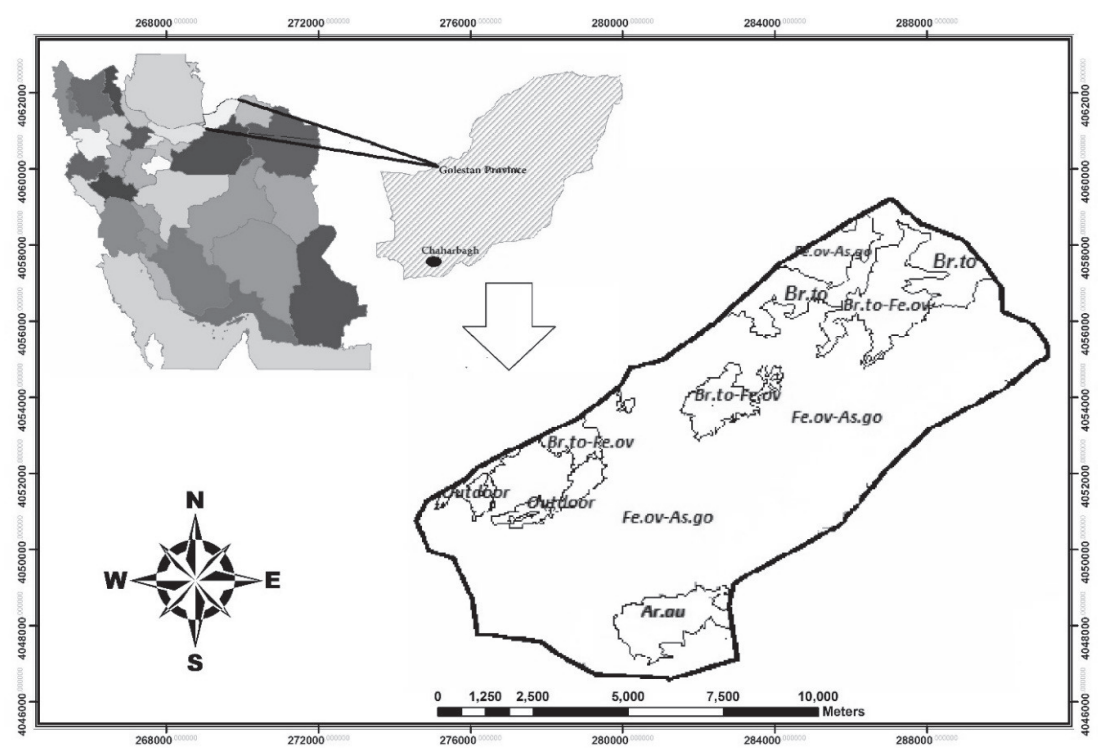

Fig. 1. Geographyof the study area.

\section{Introduction}

Distribution patterns and ecological niches are very important for many plant species because the plant species have been changed by anthropogenic activities and natural factors in rangeland ecosystems [1-2]. So illustrating the impact of these factors on vegetation distribution and spatial modeling habitats of species is essential. When the impact of environmental factors on the habitats of plant species were determined, the mapping of species plant habitat can help with sustainable planning for rangeland management [3]. There are many methods for modeling the habitat of plant species. These methods are based on the presence of species and the absence of species [4]. The MaxEnt method is one of the methods based on the presence of the species. MaxEnt is now a common species distribution modeling (SDM) tool used by conservation practitioners for predicting the distribution of species from a set of records and environmental predictors. MaxEnt is maximum entropy on the basis of machine learning programs that predict the probability distribution of an individual species' occurrence with regard to environmental limitations. The basic idea of MaxEnt is to estimate the unknown probability distribution of a specific species [5]. Researchers investigated MaxEnt modeling for predicting the potential distribution of the medicinal plant Justicia adhatoda L. in Lesser Himalayan foothills [6]. They concluded that the MaxEnt model was highly accurate with a statistically significant AUC value of 92.3. The approach could be promising in predicting the potential distribution of medicinal plant species and thus can be an effective tool in species restoration and conservation planning.

Researchers investigated the modeling of Artemisia sieberi Besser habitat distribution using the MaxEnt method in desert rangelands. Results showed that $\mathrm{pH}$ and lime content in the surface layer $(0-30 \mathrm{~cm})$ and silt percentages in both surface and sub-surface soil depths (0-30 and 30-60) had the greatest impacts on the distribution of A.sieberi in the study area. And the actual map was in good agreement with the predictive map (Kappa coefficient $=0.70$ ) [7]. Researchers invigested MaxEnt modelling for distribution of plant species habitats of rangelands (Iran), and MaxEnt was excellent in predicting distributions of plant species habitat within narrow ecological niches, e.g., Rheum ribes - A. sieberi, Seidlitzia Rosmarinus, and Cornulaca monacantha [3]. Researchers investigated halophyte species distribution modeling using MaxEnt in the surrounding rangelands of Meghan Playa in Iran. According to the results, species prefer variables such as soil texture, potassium, lime, and organic matter [8]. This species, according to the level of cover, can play a role in preventing the devastating effects of rainfall and has reduced runoff. Therefore, examining a variety of modeling techniques in order to predict the habitat of this species is very important. And because the model is based on the presence of species, they are less costly. MaxEnt model was used in this study.

\section{Materials and Methods}

\section{Study Area}

The Chaharbagh region (12,000 ha) is in the Alborz Mountains and is located northwest of Shahroud County

Table 1. Kappa index and content agreement in A. aucheri and $B$. tomentellus-F. ovina habitat.

\begin{tabular}{|c|c|c|}
\hline Habitats Plants & Kappa coefficients & Agreement \\
\hline A. aucheri & 0.05 & poor \\
\hline B. tomentellus-F. ovina & 0.51 & good \\
\hline
\end{tabular}


in Semnan County. The geographic study area is located in the southern province of Golestan (extending from $40^{\circ} 00^{\prime} \mathrm{N}$ to $28^{\circ} 04^{\prime} \mathrm{E}, 40^{\circ} 50^{\prime} \mathrm{N}$ to $27^{\circ} 45^{\prime} \mathrm{E}$ ). The study areas' altitudes were 2,208 $\mathrm{m}$ and 2,327 m. Geologically, the bedrock formations are blessed with dark-colored limestone lithology of Cretaceous to Quaternary [2]. Emberge based on regional climate, high altitude, and cold climate, mean annual temperature was $-5.6^{\circ} \mathrm{C}$ and mean annual precipitation $305 \mathrm{~mm}$, which is more precipitative in the winter and the snow [2]. Four vegetation types were identified in the study area: type 1: Artimisia aucheri; type 2: Festuca ovina - Astragalus gossypinus; type 3: Bromus tomentellus; and type 4: Bromus tomentells Festuca ovina (Fig. 1).

According to the key area, vegetation sampling was done using the random-systematic method. A square meter plot $\left(1 \mathrm{~m}^{2}\right)$ was used for sampling of vegetation [2] so that at each site $3 \mathrm{x} 50 \mathrm{~m}$ transects were considered. According to meadow plant species in the habitats and previous studies [2], along each transect we placed 10 plots of one square meter (30 plots in each type) at a distance of $5 \mathrm{~m}$. A total of 120 plots $\left(1 \mathrm{~m}^{2}\right)$ [2] were placed in each type, and then each plot was determined by the amount of cover. Soil samples were taken 0-30 $\mathrm{cm}$ (sampling of the soil due to the mountainous terrain and deep-rooted plant depths were determined within the 0-30 cm layer). Measured soil factors included texture (determined by Bouyoucos hydromerter), organic carbon (determined using Walkely and Black rapid titration, [9]), $\mathrm{pH}$ insaturation extract (determined by $\mathrm{pH}$ meter), electrical conductivity (EC, determined by conductivity meter), lime (determined using $1 \mathrm{n} \mathrm{HCl,} \mathrm{[10]),}$

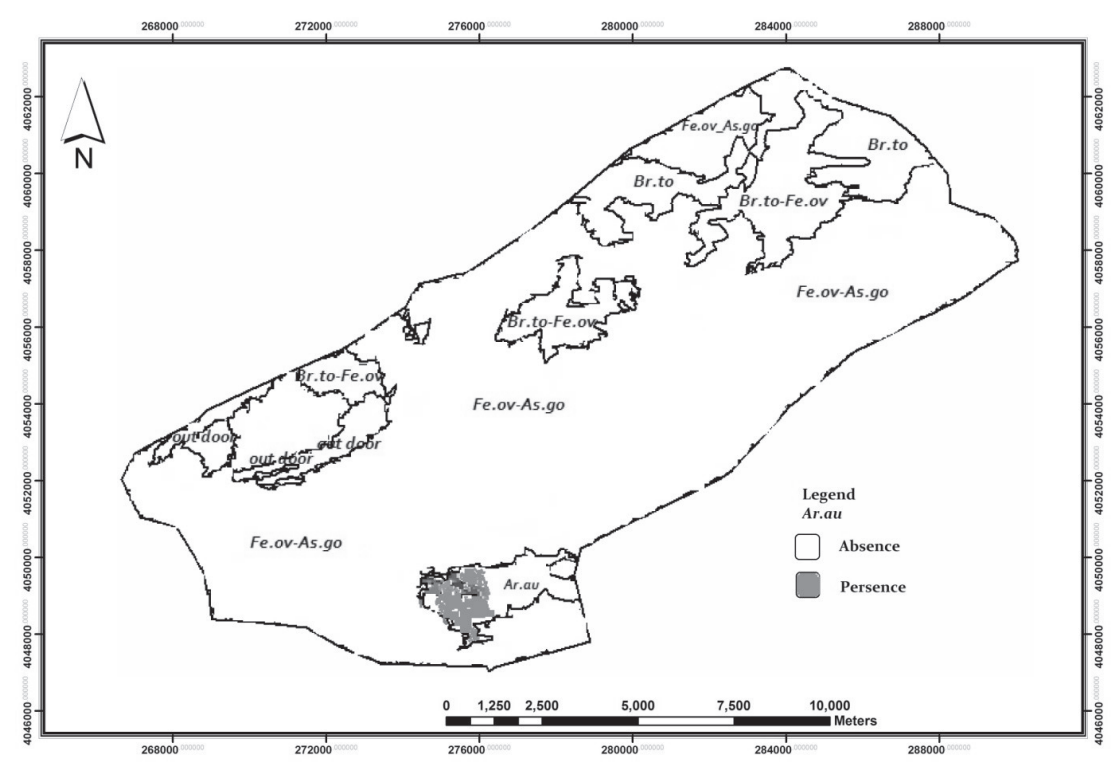

Fig. 2. Predictive and actual species distribution maps for A. aucheri (predictive maps shown darker).

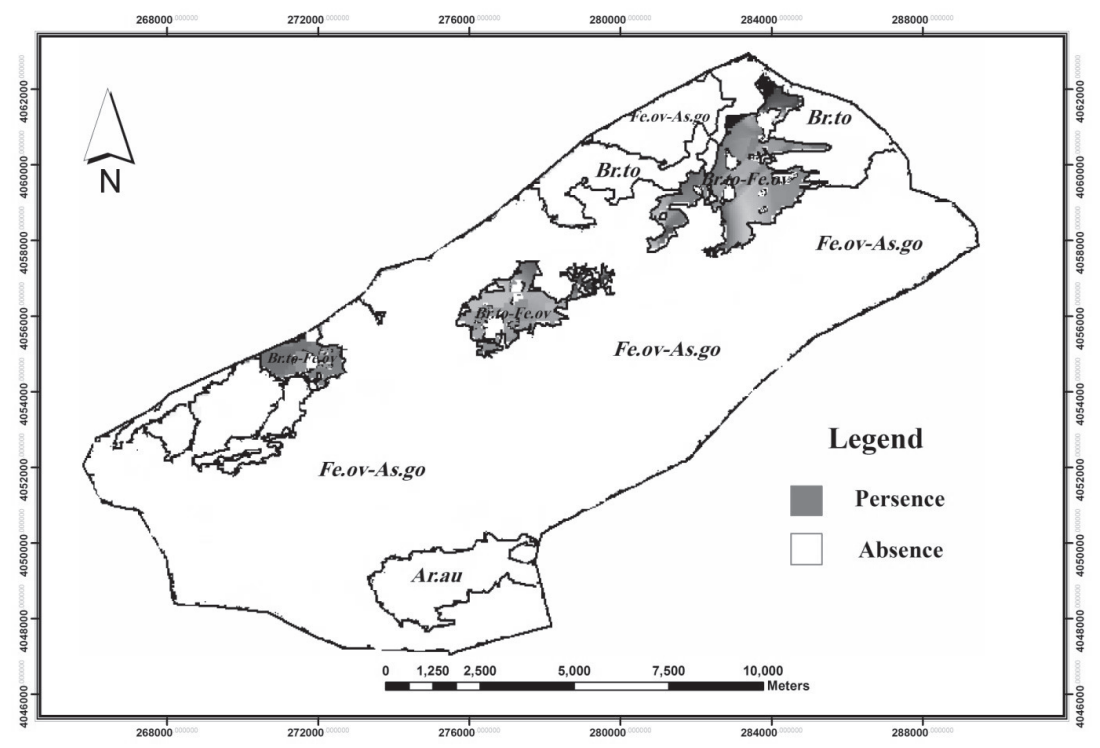

Fig. 3. Predictive and actual species distribution maps for B. tomentellus-F. ovina (predictive maps shown darker). 
and $\mathrm{N}$ determined by Kejeldal apparatus and titration method.

\section{Mapping Prediction Models}

To plant predictive mapping, it is necessary to prepare the maps of all affective factors of models. Topographic data (elevation, slope, and aspect) were derived from DEM with accuracy of $10 \mathrm{~m}$. To map soil characteristics a geoestatistical method was used, including variogram analysis and Kriging interpolation by GS+ Ver. 5.1.1, a software that is based on obtained predictive models for A.aucheri and B. tomentellus-F. ovina habitats. For modeling, we first prepared the environmental variable maps. Then these were entered into the maximum entropy software. The AUC can be interpreted as the probability that a randomly chosen diseased subject is rated or ranked as more likely to be diseased than a randomly chosen nondiseased subject. [11]. The AUC ranges from 0.5 for an uninformative model to 1 for perfect discrimination. Jackknife analysis was also used to determine the importance of variables. We used

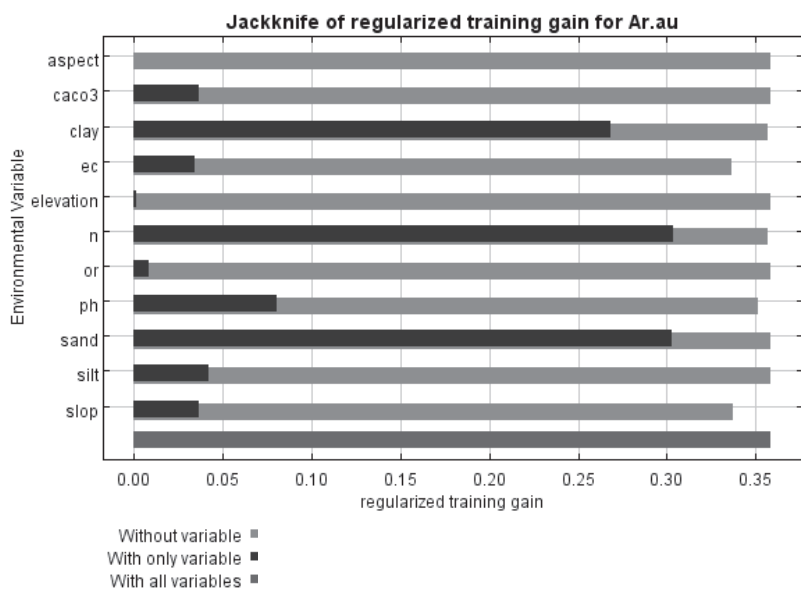

Fig. 4. Jackknife results of variable importance (sand, clay, and $\mathrm{N}$ ) for A. aucheri.

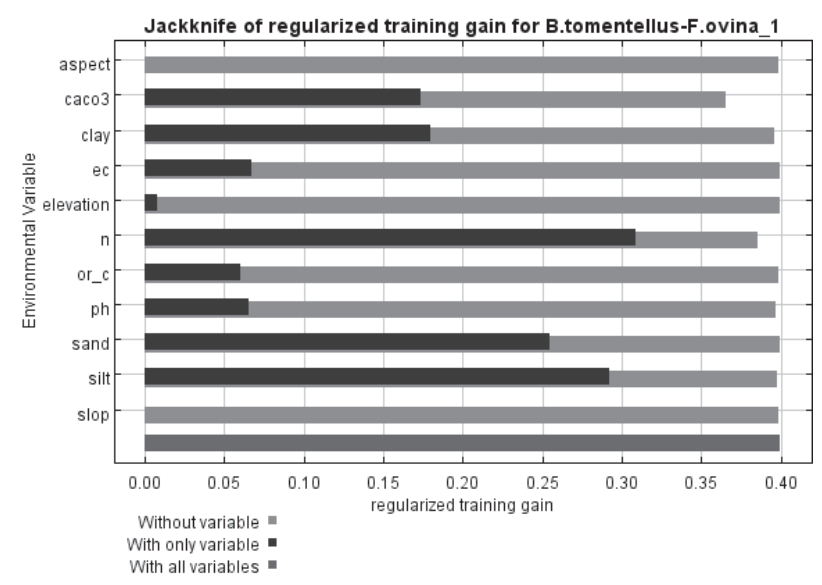

Fig. 5. Jackknife results of variable importance (N, silt, sand, and clay) for B. tomentellus-F. ovina.
MaxEnt 3.1 software, which estimates the probability of species presence ranging from 0 to 1 , in which 0 and 1 stand for the lowest and highest probability rates, respectively. Because of continuous output of MaxEnt, it is necessary to determine an optimal threshold for determining the presence or absence of the target species [7]. After determining the optimal threshold using equal sensitivity and specificity method, species presence or absence maps were generated and their coincidence with the actual maps were investigated through calculating the kappa coefficient in the IDRISI Selva 17 software [2].

\section{Results and Discussion}

The results of MaxEnt modeling consist of species distribution maps, importance of predictor variables, and model evaluation with receiver operating characteristics (ROC) curves.
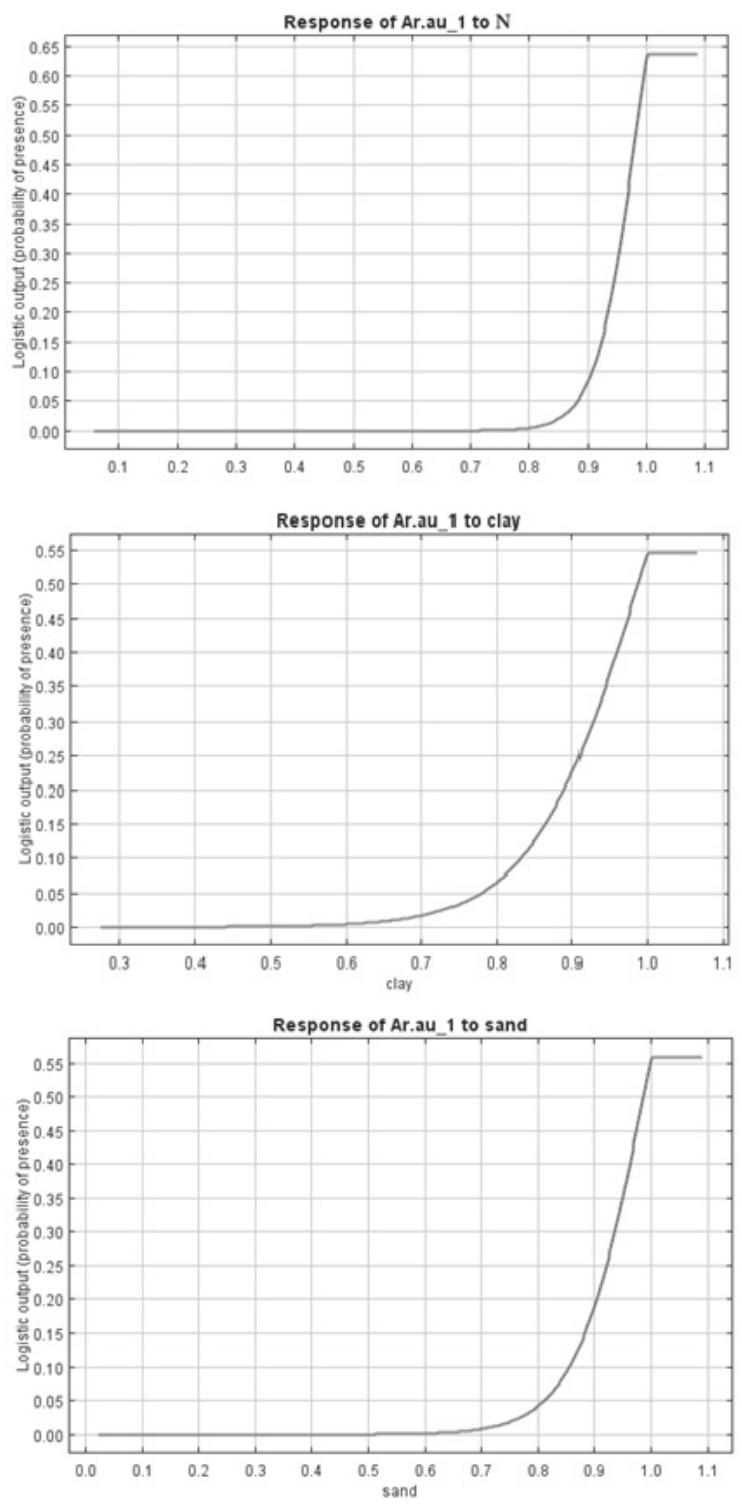

Fig. 6. Response curves of the most influential predictors for $A$. aucheri habitat. 


\section{Species Distribution Maps}

After determining the optimal threshold, the agreement of these species distribution maps of three desired species that were derived using the layers of environmental variables at each habitat was checked with the actual maps and then determined by measuring the Kappa coefficient using IDRISI Selva 17 software. Based on Table 1, predictive maps of $A$. aucheri habitat had poor agreement (Kappa index $=0.05$ ) but B. tomentellus- $F$. ovina habitat had good agreement (Kappa index $=0.51)$ [12] (Figs 2-3).

\section{Importance of Predictor Variable}

Based on the jackknife operation results (Figs 4-5), $\mathrm{N}$, sand, and clay were identified as the most important variables when used individually in the A. aucheri habitat. The results showed that the species A.aucheri has good habitat on the higher slopes in the study area. These results indicated the same when other variables such as elevation in $A$. aucheri habitat were individually used. The most important variables were identified as N, sand, silt, clay, and lime in the B. tomentellus-F. ovina habitat. The results showed that the B. tomentellus- $F$. ovina species has suitable habitat on the lower slopes in the study area. So the aspect and elevation had an impact on the B. tomentellus-F. ovina habitat.

\section{Response Curves}

Response curves represent the relationships of environmental variables and suitable habitat distribution of plant species (Figs 6-7). This curve can provide useful information about the required environmental threshold for optimal growth of plant species. Response curve
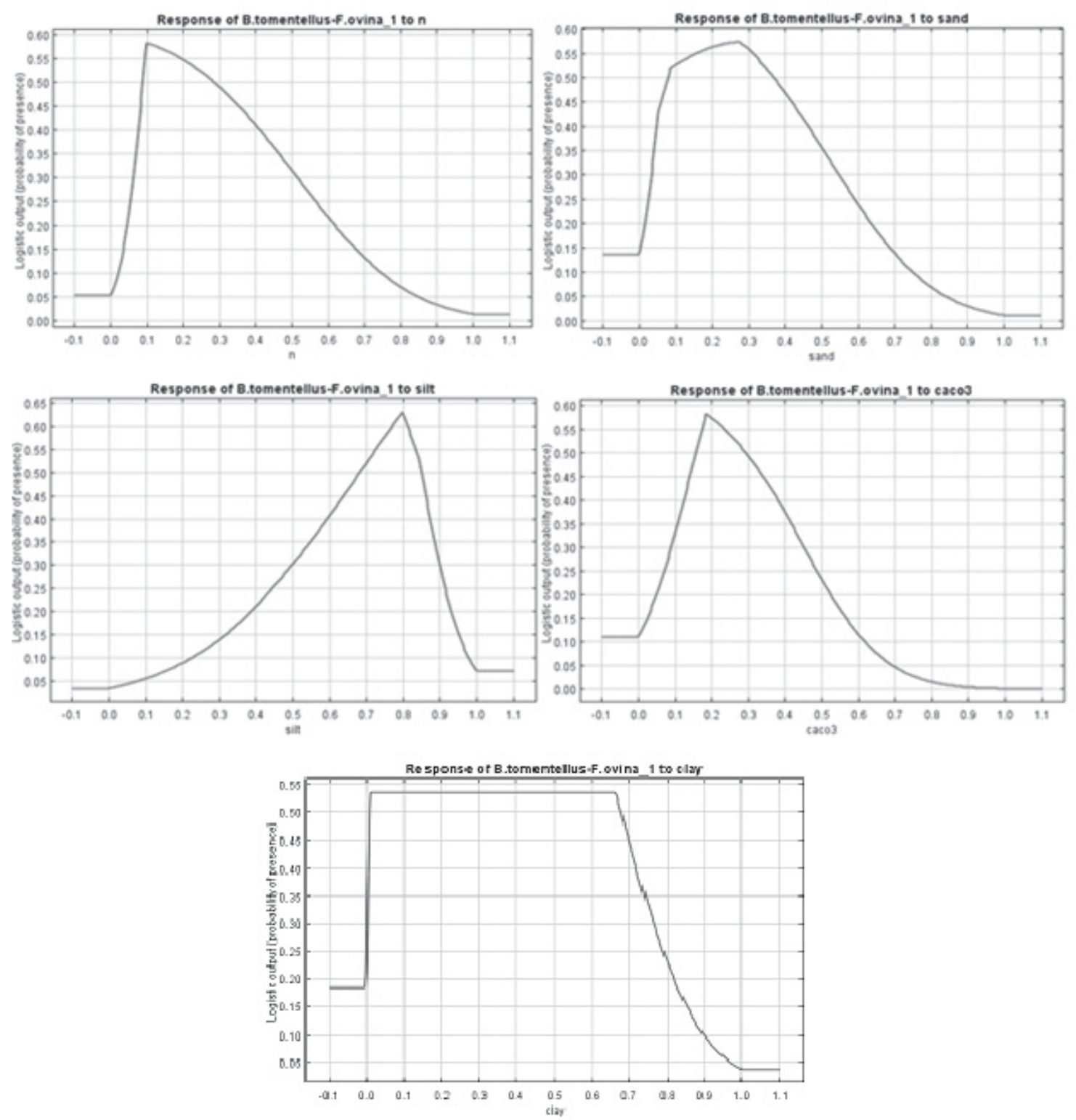

Fig. 7. Response curves of the most influential predictors for B. tomentellus-F. ovina habitat. 
analysis of the most important variables of A.aucheri showed that the increased $\mathrm{N}$ amount $(0 / 75-0 / 86)$ in surface soil depth and the increased sand (56-58\%) and clay (20-22\%) amounts and response curve analysis of the most important variables of $B$. tomentellus-F. ovina showed that the increased $\mathrm{N}$ amount $(8-9 \%)$ in surface soil depth and the increased sand $(40-46 \%)$ and silt (40-50\%) and clay (10-14\%) and lime (12-15\%) amount in Figs 6-7.

\section{Receiver Operating Characteristics Curves}

In addition to measuring the kappa coefficient for the agreement of desired maps, classification accuracy of predictive habitat models was evaluated using the area under ROC curves. According to the obtained AUC values and AUC classification, model predictive accuracy of A.aucheri habitat was assessed as an acceptable level (AUC $=0.77$; AUC for accuracy of data entry to software, but the Kappa index was used to determine the precision of production maps; Fig. 8) and model predictive accuracy of $B$. tomentellus $-F$. ovina habitat was assessed as an acceptable level (AUC $=0.75$ ). So the MaxEnt model has high accuracy for predicting habitat.

a)

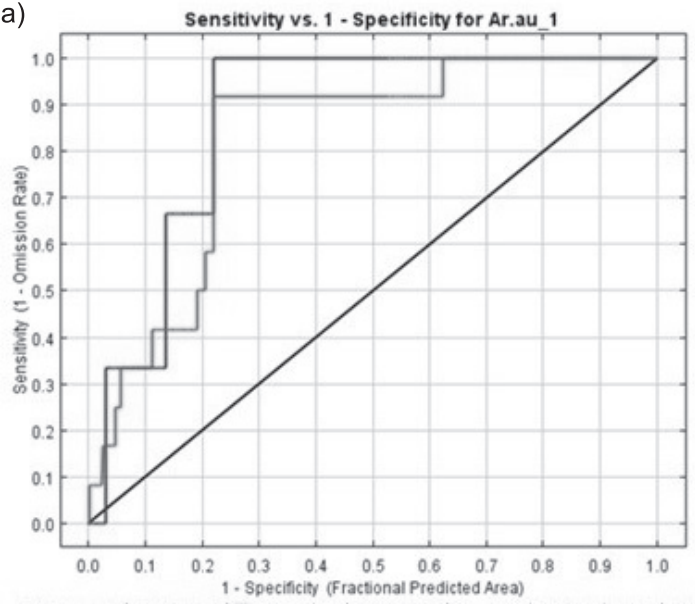

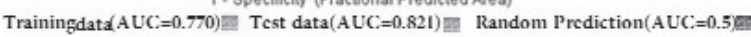

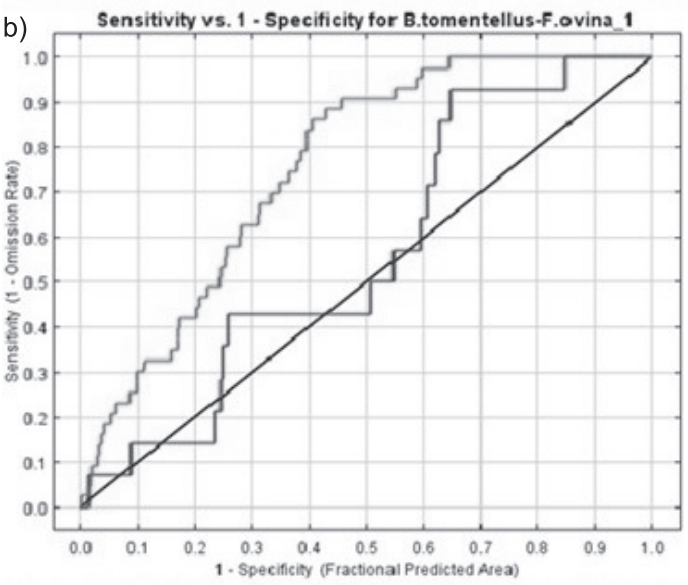

Training data $($ AUC $:=0.757)$ = Test data $($ AUC $=0.565)$ Random Prediction $($ AUC $=0.5)$
The maximum likelihood explanation of MaxEnt opens for calculation of residuals for each grid cell in data sets used for model parameterization and data sets used for model evaluation, which can then be used to analyze the spatial structure by geostatistical methods as suggested, among others, by [13]. Furthermore, the possibility for incorporating spatial autoregressive terms in MaxEnt models should be further explored. Generalized linear mixed models with autoregressive terms have been shown to improve the performance of other regression-type modelling methods substantially (e.g., [14-15], but see [16]). MaxEnt model indicated that habitat distribution of A.aucheri is mainly related to soil characteristics. The MaxEnt model's internal jackknife test of variable importance showed that $\mathrm{N}$ and sand content were the most important predictors of $A$. aucheri habitat distribution. These variables presented higher gain (which contained the most information) as compared to the other variables. Studying the habitat requirements of $A$. aucheri indicated that the highest presence probability of A.aucheri occurred in the soils with high $\mathrm{N}(0 / 75-0 / 86)$ content and sand (56-58\%) content and clay content (20-22\%). Therefore, A. aucheri is affected by soil texture [2] and, therefore, A.aucheri is grown in the soil texture sandy-clay-loam. The results showed that A.aucheri habitat slope preferred the 35\% range. Topographic directly through changes and adjustments based on environmental factors - and indirectly by affecting soil formation - has a major impact on plant communities [17]. Checking the A.aucheri species by MaxEnt models, it was shown that the cause of building lime soil unsuitable for A.aucheri species and removal of these species, if lime percentage is reduced, in the root zone created conditions for the plant, the possibility of the presence of A.aucheri species increases [18]. But The MaxEnt model's internal jackknife test of variable importance showed that $\mathrm{N}$ and silt content were the most important predictors of $B$. tomentellus-F. ovina habitat distribution. These variables presented higher gains (that contained the most information) as compared to the other variables. Studying the habitat requirements of $B$. tomentellus-F. ovina indicated that the highest presence probability of $B$. tomentellus-F. ovina occurred in the soils with high $\mathrm{N}(8-9 \%)$ and silt (40-50\%) and sand (40-46\%) and clay (10-14\%) and lime (12-15\%) content. Therefore, A.aucheri and B. tomentellus-F. ovina are affected by soil texture [2]. Due to the effect of soil, water content and plant available nutrients and ventilation are important for vegetation distribution [19]. Other researchers have demonstrated the relationship between vegetation and soil characteristics [8-18]. According to the obtained results, the predicted mapping for $B$. tomentellus-F. ovina habitat was better (Kappa index $=0.51)$. But for A.aucheri habitat the precision of the predicted mapping was poor (Kappa index $=0.05$ ). The MaxEnt method was more accurately producing maps for $B$. tomentellus- $F$. ovina habitat.

Fig. 8. ROC curves of sensitivity vs. specificity. 


\section{Conclusions}

Using the MaxEnt method can determine the ecological thresholds of the important and dominant mountainous regions plant species of A.aucheri and B. tomentellus- $F$. ovina. Identifying the potential habitat of plant species using modeling methods can play an important role in introducing plant species in areas of similar condition.

\section{References}

1. ZARE CHAHOUKI M.A. Multivariate Analysis Techniques in Environmental Science. Erath and Environment Science, 68, 1, 2011.

2. ZARE CHAHOUKI M.A., ESFANJANI J. Predicting potential distribution of plant species by modeling techniques in southern rangelands of Golestan, Iran. Journal of Range Management and Agroforestry, 66, 36, 2015.

3. ZARE CHAHOUKI M.A., PIRI SAHRAGARD H. MaxEnt Modelling for Distribution of Plant Species Habitats of Rangelands (Iran). Polish Journal of Ecology, 453, 64, 2016.

4. SOHEL SI., AKHTER S., ULLAH H., HAQUE E., RAN P. Predicting impacts of climate change on forest tree species of Bangladesh: evidence from threatened Dysoxylum binectariferum (Roxb.) Hook.f. ex Bedd. (Meliaceae). Journal of iforest, 154, 10, 2016.

5. PHILLIPS S.J., ANDERSON R.P., SCHAPIRE R.E. Maximum entropy modeling of species geographic distributions. Ecology Modelling, 231, 190, 2006.

6. XUE-QING YANGA L., KUSHWAHAB S.P.S., SARANB S., JIANCHUXUC P.S. MaxEnt modeling for predicting the potential distribution of medicinal plant, Justicia adhatoda L. in Lesser Himalayan foothills- Ecology Engi, 83, 51, 2013.

7. PIRI SAHRAGARD H., ZARE CHAHOUKI M.A. Modeling of Artemisia sieberi Besser Habitat Distribution Using Maximum Entropy Method in Desert Rangelands. Journal of Rangeland Science, 93, 6, 2016.

8. BAGHERI H., GHORBANI A., ZARE CHAHOUKI M A., JAFARI A.A., SEFIDY K. Halophyte Species Distribution Modeling With MaxEnt Model In The Surrounding Rangelands Of Meghan Playa in Iran. Applied Ecology and Enviromental Research, 1473, 15, 2017.

9. BLACK C.A. Methods of soil analysis. American Society of Agronomy. 771 (2), 1979.

10. JACKSON M.L. Soil Chemical Analysis- Prentice-Hall of India, New Delhi, 1967.
11. HAJIAN-TILAKI K. Receiver Operating Characteristic (ROC) Curve Analysis for Medical Diagnostic Test Evaluation. Caspian Journal Internal Medicine, 627, 4, 2013.

12. MONSERUD R.A., LEEMANS R. Comparing global vegetation maps with the kappa statistic. Journal of Ecology Modelling, 275, 62, 1992.

13. DORMANN C. Modelling species' distributions. In: Jopp, F., Reuter, H. \& Breckling, B. (eds), Modelling complex ecological dynamics: an introduction into ecological modelling. Springer, Berlin, 179, 2011.

14. BINI L.M., DINIZ-FILHO A.F., RANGEL T.F.L.V.B., AKRE T.S.B., ALBALADEJO R.G., ALBUQUERQUE F.S., APARICIO A., ARAÚJO M.B., BASELGA A., BECK J., BELLOCQ, M.I., BÖHNING-GAESE K., BORGES, P.A.V., CASTRO-PARGA I., CHEY V.K., CHOWN S.L., DE MARCO P.J., DOBKIN D.S., FERRER-CASTÁN D., FIELD, R., FILLOY J., FLEISHMAN E., GÓMEZ J.F., HORTAL J., IVERSON J.B., KERR J.T., KISSLING W.D., KITCHING I.J., LEÓN-CORTÉS J.L., LOBO J.M., MONTOYA D., MORALES-CASTILLA I., MORENO J.C., OBERDORFF T., OLALLA-TÁRRAGA M.Á., PAUSAS J.G., QIAN, H., RAHBEK C., RODRÍGUEZ M.Á., RUEDA M., RUGGIERO A., SACKMANN, P., SANDERS N.J., TERRIBILE, L.C., VETAAS O.R., HAWKINS B.A. Coefficient shifts in geographical ecology: an empirical evaluation of spatial and non-spatial regression. Journal of Ecological, 193, 32, 2009.

15. CARROLL C., JOHNSON D.S., DUNK J.R., ZIELINSKI W.J. Hierarchical Bayesian spatial models for multispecies conservation planning and monitoring. Journal of Conservation Biology. 1538, 24, 2010.

16. TINGLEY R., HERMAN T.B. Land cover data improve bioclimatic models for anurans and turtles at a regional scale- Bio journal, 1656, 36, 2009.

17. CLASSEN A., SUNDQVIST M., HENNING J A., NEWMAN G., MOORE J., CREGGER M., MOORHE L., PATTERSON C. Direct and indirect effects of climate change on soil microbial and soil microbial-plant interactions: What lies ahead?. Journal of Ecospher, 135, 8, 2015.

18. ZARE CHAHOUKI M.A., KHALASI AHVAZI L., AZARNIVAND $\mathrm{H}$. Environmental factors affecting distribution of vegetation communities in Iranian Rangelands. Vegetos Journal, 1, 23, 2010.

19. RANGEL T.F.L.V.B., DINIZ-FILHO J.A.F., BINI L.M. Towards an integrated computational tool for spatial analysis in macro ecology and biogeography. Global Ecology and Biog, 321, 15, 2006. 
